\title{
Adsorption Isotherms studies of the removal of Indigo Blue dye from aqueous solution using chemically modified coconut shell
}

\author{
*Olaniyi K. Yusuff ${ }^{1}$, Modinah A. O. Abdul Raheem ${ }^{1}$, Omowunmi D. Agboola ${ }^{1}$
}

${ }^{1}$ Department of Chemistry, University of

Ilorin Nigeria

\section{* Correspondnce \\ Olaniyi Kamil Yusuff \\ Department of Chemistry, Faculty of \\ Physical Sciences, University of Ilorin, \\ Ilorin, Nigeria.}

E-mail: okyusuff@gmail.com

\begin{abstract}
:
Introduction: The conversion and utilization of agricultural wastes in environmentally friendly processes have transformed these materials into useful rather than waste materials.

Aim: This study investigates the adsorption of indigo blue dye from aqueous solution onto coconut shell, a low cost agricultural waste material in a batch process.

Materials and Methods: Pulverized coconut shell was chemically modified and characterized using the Fourier Transform Infra Red spectroscopy and Scanning Electron Microscopy. Adsorption process using the chemically modified coconut shell was studied as a function of $\mathrm{pH}$, initial dye concentration, adsorbent dose, and contact time. The adsorption equilibrium data were analyzed with Langmuir, Freundlich and Temkin isotherm models.
\end{abstract}

Results: The results revealed that percentage of the indigo dye adsorbed from aqueous solution varied linearly with the adsorbent dose, concentration and time with maximum percentage dye adsorption of $88.4 \%$ at $70 \mathrm{mg}$ dosage, $95.8 \%$ at $0.05 \mathrm{mg} / \mathrm{L}$ concentration and $90 \%$ at 1 hr contact time but varies non-linearly with $\mathrm{pH}$ with maximum percentage dye adsorption of $92.9 \%$ attained at $\mathrm{pH}$ of 5 . The adsorption equilibrium data were analyzed with Langmuir, Freundlich and Temkin isotherm models with the Langmuir isotherm having the best fit to the adsorption process with $R^{2}$ value of 0.998 . The experimental data were best described by the pseudo-second order kinetics model. FTIR analyses reveal that the adsorption process was through a chemical interaction of the dye with some functional groups at the surface of the adsorbent

Conclusion: The chemically modified coconut shell is an effective adsorbent for the removal of indigo dye from aqueous solution is by chemisorption process with the adsorbent surface energetically homogeneous $(n<1)$.

Keywords: Adsorption, Indigo blue dye, Coconut Shell, Kinetics, Aqueous solution. 


\section{INTRODUCTION}

Indigo blue dye is a vat dye that has found extensive use in the industries. Apart from its use as a textilecolouring agent, indigo and its derivatives are also used as an additive in pharmaceutical tablets and capsules and for medical diagnosis [1 - 4]. Textile industries consume substantial volumes of dyes for wet processing of textiles, the chemicals in these dyes range from inorganic compounds and elements to polymers and organic products. Such extensive use of dyes poses problems such as reducing water transparency, affecting photosynthetic process, and solubility of gases in the body of the water [5]. Effluents from these textile industries require pretreatment for colour prior to disposal into receiving water bodies. This is because this dye-bearing waste water imparts toxicity to aquatic life and damage the aesthetic nature of receiving water bodies' environment [6].

Several methods have been reported for quantitative determination of Indigo blue, including chromatographic, voltametric and spectrophotometric ones. New treatment technologies have been developed in order to meet the legal requirements regarding effluent disposal of this dye as well as to reduce the operating costs of such processes. The Indigo dye is insoluble in water and must be reduced i.e. the oxygen must be removed in the presence of alkali by a reducing agent such as thiourea dioxide (thiox), sodium hydrosulphite, zinc or bacteria before its application. Upon reduction, indigo becomes colourless and water soluble. In reduced state, indigo has a high affinity for cellulosic fibers and enters the open spaces of the fiber. The dyed fibers are then exposed to air, which oxidizes the dye molecule back to its insoluble form. Thus, Indigo dye works by oxidation - reduction reaction (redox reaction). The insoluble dye particles are trapped inside the fiber, colouring them permanently blue. Unlike most dyes, indigo forms a mechanical, not chemical bond with the fabrics [7]

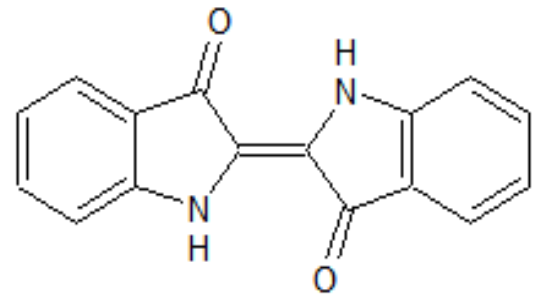

Indigoblue

\section{Figure 1: Indigo blue}

Coconut shell (Cocos Nucifera L.) has been used as a low cost alternative adsorbent for the removal of pollutants (dyes and other natural and inorganic substances) from natural waters. Also, the retention capacity of several metallic ions in aqueous solutions has been previously reported [8] using coconut fiber as the adsorbent. This is a sustainable alternative because of waste reuse.

Adsorption has been reported to be an effective process for colour removal from dye wastewater [9-
11]. The term 'adsorption' was proposed by du BoisReymond but introduced to the literature by Kayser [12] and has found diverse applications from being widely used for the removal of solutes from solutions to the removal of gases from atmospheric air. The extent of adsorption depends on the nature of adsorbent especially its porosity and surface areas. The size and distribution of the macro and micro pores of the adsorbent are key features for effective adsorption, as they determine the ions or molecules that can be adsorbed [13].

Adsorption process can utilizes agricultural materials as well as a wide variety of micro-organisms in dead, pretreated and immobilized form as the adsorbing agents. These materials are cheap to get, environmentally friendly and carry wide range of binding sites for the adsorbate molecules [14].

This present study investigates the use of chemically activated coconut shell as an effective adsorbent for the removal of Indigo blue dye from solution. Adsorption equilibrium data were analysed with Langmuir isotherm [15], Freundlich isotherm [16] and Temkin isotherm [17] models. Adsorption kinetics models and the intraparticle diffusion were used to describe the adsorption processes.

\section{MATERIAL AND METHODS}

\subsection{Apparatus and Reagents}

Measuring cylinder, standard conical flasks, Volumetric flasks, Pipette, Burette, filter paper, funnel, paper tape, $\mathrm{pH}$ meter, Weighing balance, water bath shaker, UVVisible spectrophotometer (Beckman coulter), Schimadzu IRAffinity-1S spectrophotometer, Phenonprox Scanning Electron Microscope JEOLJSM-35CF model.

All chemical reagents used were of analytical grade from BDH chemicals. De-ionized water was used throughout the experiment.

\subsection{Modification and Characterization of the Adsorbent (Coconut Shell)}

The adsorbent, coconut (Cocos nucifera L.) shell was obtained from a local coconut processing mill in Ikeja, Lagos state, Nigeria. The Indigo blue dye was purchased from a local market in Abeokuta, Ogun state, Nigeria. Indigo blue has molecular formula $\mathrm{C}_{16} \mathrm{H}_{10} \mathrm{~N}_{2} \mathrm{O}_{2}$ (Mol. wt. $262.27 \mathrm{~g} / \mathrm{mol}$ ). It was used without further purification, but just reduction, so as to make it water soluble for the sake of the experiment. Reagents for reduction of the dye include sodium thiosulphate $\left(\mathrm{Na}_{2} \mathrm{~S}_{2} \mathrm{O}_{4}\right)$ and dilute $3 \mathrm{M} \mathrm{NaOH}$ solutions.

The Coconut shell was modified in a three-step procedure to obtain optimum adsorption of the indigo dye. The reagents for coconut shell's surface treatment were aqueous solutions of $5 \%, 10 \%, 15 \%$, and $20 \%$ composition of sodium hydroxide $(\mathrm{NaOH})$, hydrogen peroxide $\left(\mathrm{H}_{2} \mathrm{O}_{2}\right)$ of the same composition, and $0.25 \%, 0.5 \%, 0.75 \%$, and $1 \%$ potassium permanganate $\left(\mathrm{KMnO}_{4}\right)$. The coconut shell was firstly treated with the $\mathrm{NaOH}$ solution, then with the $\mathrm{KMnO}_{4}$ solution and finally with the $\mathrm{H}_{2} \mathrm{O}_{2}$ solution, dried at $90{ }^{\circ} \mathrm{C}$ and cooled to room temperature [18]. The 
modified shell was then air- dried, pulverized and sieved to $500 \mu \mathrm{m}$ size. The pulverized adsorbent was characterized before and after the adsorption process using the Scanning Electron Microscopy (SEM) and Fourier Transform Infra Red (FTIR) spectroscopy.

\subsection{Preparation of adsorbate (Dye Stock)}

The dye stock solution was prepared by firstly weighing $0.02 \mathrm{~g}$ of Indigo blue dye into a beaker containing $50 \mathrm{ml}$ of water, after which $0.12 \mathrm{~g}$ of $\mathrm{Na}_{2} \mathrm{~S}_{2} \mathrm{O}_{4}$ and $1.2 \mathrm{ml}$ of $3 \mathrm{M} \mathrm{NaOH}$ were added.

The solution was then heated at a temperature of 50 ${ }^{\circ} \mathrm{C}$ till the colour changed from green to blue; this was done to ensure reduction of dye into its leuco-soluble form as indigo dye is insoluble in water, unless it is reduced to the leuco-soluble form [19] (Figure 2).

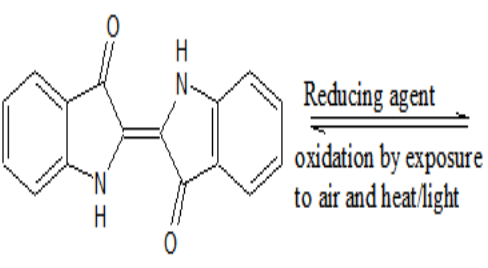

Indigo blue

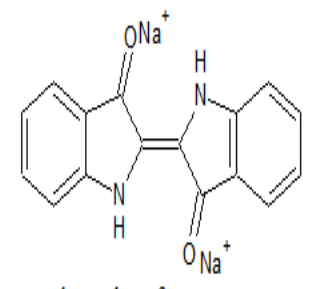

leuco-base form
Figure 2: Reduction of insoluble Indigo blue to soluble leuco-base form of Indigo blue.

The resulting solution made was transferred to a 100 $\mathrm{ml}$ volumetric flask and made up to mark to prepare $0.2 \mathrm{~g} / \mathrm{l}$ stock solution of the dye. $0.4,0.8,1.2,1.6$ and $2.0 \mathrm{mg} / \mathrm{L}$ concentrations were then prepared from the stock solution by serial dilution and used to obtain a calibration curve (Figure 3).

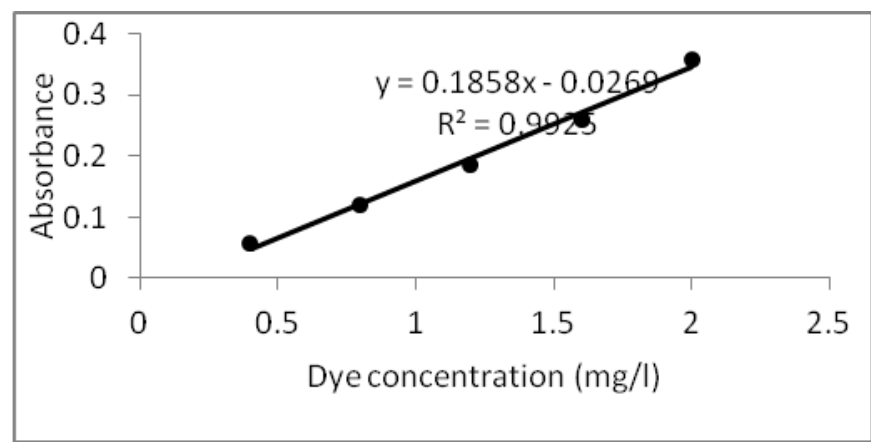

Figure 3: Calibration curve of indigo dye at concentration range from 0.4 to $2.0 \mathrm{mg} / \mathrm{L}$

\subsection{Adsorption Batch process}

For each experiment, $25 \mathrm{ml}$ of $0.2 \mathrm{mg} / \mathrm{L}$ dye solution (concentration was varied in the case of effect of initial concentration) was agitated with $0.5 \mathrm{~g}$ of Pulverized Coconut shell (except for effect of adsorbent dose, where the mass of shell was varied) at a constant speed of 200 rpm for 3 hours in a shaker after which they were centrifuged at $4,000 \mathrm{rpm}$ for 20 minutes to separate the supernatant. The experiments were carried out in triplicate after which $5 \mathrm{ml}$ of each supernatant is taken and analyzed for the residual dye content by UV - Visible Spectrophotometer (Beckman coulter) using a $\lambda_{\max }$ of $640 \mathrm{~nm}$.
The effect of initial concentrations of the dye on the adsorption process was determined in the range 0.05 $-0.3 \mathrm{mg} / \mathrm{L}$ dye concentration. The effect of the initial $\mathrm{pH}$ on the adsorption capacity was investigated in the $\mathrm{pH}$ range of $2-8$. The effect of time on adsorption process was studied at the time range of $3-7$ hours contact time. The effect of adsorbent dose on the adsorption process was studied using $0.1,0.3,0.5$, $0.7,0.9,0.11,0.13$ and $0.15 \mathrm{~g}$ of the adsorbent.

\section{RESULTS AND DISCUSSION}

\subsection{Characterization of the Adsorbent}

\subsubsection{Scanning Electron Microscope Analysis}

The Scanning Electron Microscope image of the Coconut shell was taken to have better understanding of the surface morphology of the adsorbent before and after the adsorption experiment. The SEM micrographs at $30 \mu \mathrm{m}$ and $200 \mu \mathrm{m}$ magnifications for the modified coconut shell before the adsorption experiments; Figure $4(a-b)$, show a rough surface with irregular pore sizes for the modified coconut shell, this may be attributed to the crystallization of $\mathrm{NaOH}$ solution (used for modification) and the drying at temperature $70{ }^{\circ} \mathrm{C}$ for 3 hours. The increased surface roughness of coconut shell implies an increasing amount of the exposed cellulose and the strength of natural coconut shell.The SEM micrographs at $30 \mu \mathrm{m}$ and $200 \mu \mathrm{m}$ magnifications for the modified coconut shell after the adsorption experiments; Figure $4(c-d)$, show a rather more smoothen surface, indicating that shell pores have been filled with dye molecules and are no longer visible.

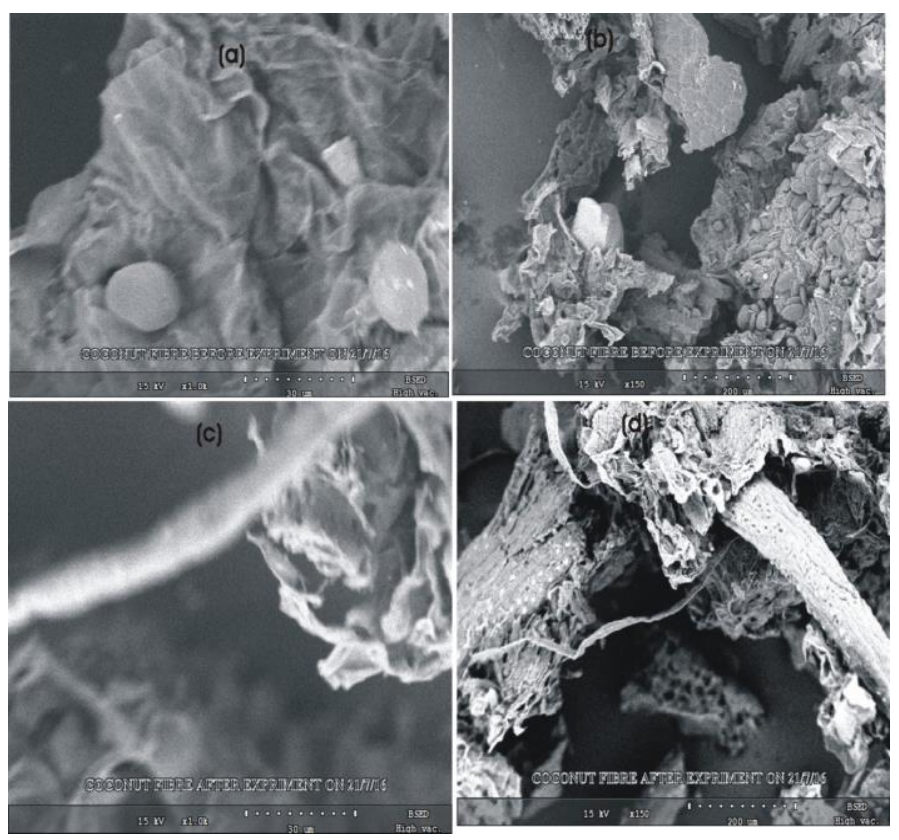

Figure 4: Scanning Electron Micrograph of the crude Coconut shell at (a) $30 \mu \mathrm{m}$ and (b) $200 \mu \mathrm{m}$ magnifications, (c) $30 \mu \mathrm{m}$ and (d) $200 \mu \mathrm{m}$ magnifications after adsorption process 


\subsubsection{FTIR Spectral Analysis}

FTIR spectroscopy provides structural and compositional information on the functional groups present in the samples. The functional groups present in the proximate composite of the coconut shell were analyzed by Fourier transform infrared (FTIR) spectroscopy. Figure $5(\mathrm{a}-\mathrm{b})$ shows IR spectra of raw coconut shell and dye loaded coconut shell respectively. The spectra showed a number of absorption peaks, indicating the complex nature of the coconut shell. Comparison of the spectra before and after the adsorption process shows that a total number of 15 peaks out of the 21 changed. Some peaks like $2299.15 \mathrm{~cm}^{-1}$ representing $\mathrm{C} \equiv \mathrm{N}$ group, $1112.93 \mathrm{~cm}^{-1}$ showing a broad band of $\mathrm{C}-\mathrm{O}$ and $420.48 \mathrm{~cm}^{-1}$ an alkyl halide stretch that were present initially in the shell disappeared completely after adsorption process. There were also shifts in peaks like $1653.00 \mathrm{~cm}^{-1}$ to $1654.92 \mathrm{~cm}^{-1}$ indicating a broader amide stretch, $1388.75 \mathrm{~cm}^{-1}$ to 1384.89 indicating an alteration in the already weak $\mathrm{N}-\mathrm{O}$ group that made it weaker and no longer broad. The shift in the peak at $1157.29 \mathrm{~cm}^{-1}$ to $1165.00 \mathrm{~cm}^{-1}$ showing a stronger and broader band of $\mathrm{C}-\mathrm{O}$ which indicates that there is presence of a new substance which is possibly a dye molecule, 1033.85 $\mathrm{cm}^{-1}$ to $1070.49 \mathrm{~cm}^{-1}$ indicating a longer stretch, $894.97 \mathrm{~cm}^{-1}$ to $891.11 \mathrm{~cm}^{-1}$ indicating a slight change in the alkene $=\mathrm{C}-\mathrm{H}$ bending, $765.74 \mathrm{~cm}^{-1}$ to $754.17 \mathrm{~cm}^{-1}$ indicating a slight $\mathrm{C}-\mathrm{Cl}$ stretch, $580.57 \mathrm{~cm}^{-1}$ to 576.72 $\mathrm{cm}^{-1}$ and $516.92 \mathrm{~cm}^{-1}$ to 518.85 also showing a slight change in the $\mathrm{C}-\mathrm{Br}$ stretch. New wavelength of peaks $1994.40 \mathrm{~cm}^{-1}$ shows a $\mathrm{C}=\mathrm{C}$ asymmetric stretch, $1799.59 \mathrm{~cm}^{-1}$ indicates a $\mathrm{C}-\mathrm{O}$ acyl halide and 630.72 $\mathrm{cm}^{-1}$ showing the addition of another $\mathrm{C}-\mathrm{Cl}$, all these changes indicates the involvement of the functional groups in the adsorption process and that the adsorption type is mostly Chemisorption.

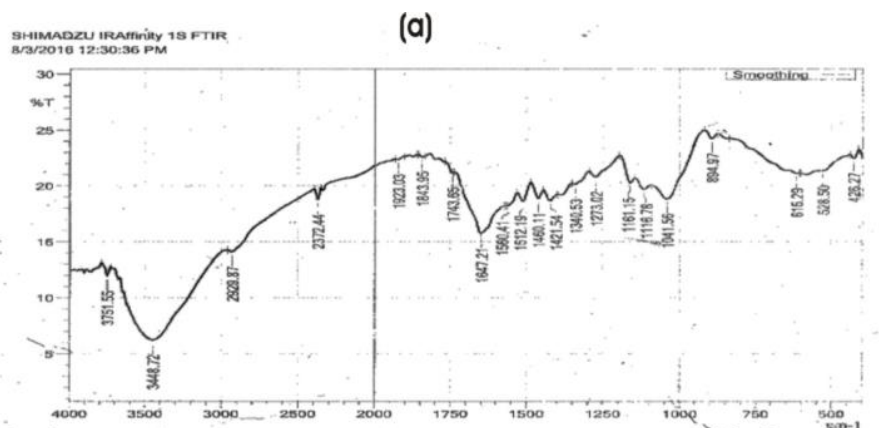

(b)

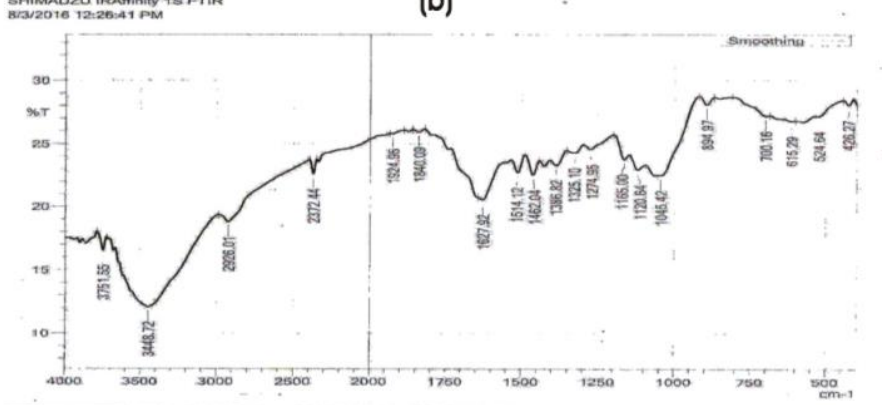

Figure 5: FTIR result of the modified coconut shell (a) before and (b) after adsorption of Indigo blue dye respectively

\subsection{Adsorption Laboratory Batch Experiment}

\subsubsection{Effect of $\mathrm{pH}$}

The effect of the variation of $\mathrm{pH}$ on the adsorption process is shown in Figure 6(a). The initial $\mathrm{pH}$ value for the reduced form of the dye before any further adjustment was 11 which is $\mathrm{pH}$ for a strong base. Maximum adsorption of $92.9 \%$ occurred at a weak acid $\mathrm{pH}$ of 5 . This may likely be due to less $\mathrm{OH}^{-}$ions competing with the $\mathrm{OH}^{-}$ion of the dye for adsorption sites at that $\mathrm{pH}$ and also because of the functional group in the coconut shell that consist of more acidic group than basic functional group, thereby increasing adsorption due to increase in electrostatic force between the $\mathrm{H}^{+}$ion on the coconut shell and $\mathrm{OH}^{-}$ion of the dye molecules.

\subsubsection{Effect of adsorbent dose}

The percentage of dye removal increased with an increase in adsorbent dosage from $10 \mathrm{mg}$ to $70 \mathrm{mg}$, Figure 6 (b) which had $88.4 \%$ removal. The increase in adsorption with adsorbent dosage can be attributed to an increase in the adsorption surface area and availability of more adsorption sites. However, on further increase of adsorbent dose, a decrease in percentage adsorption occurred and this may be as a result of overlapping or aggregation of adsorption sites resulting in a decrease in the total adsorption surface area available to the dye and an increase in the diffusion path length.

\subsubsection{Effect of Initial dye Concentration}

It was found that the percentage of adsorption decreased with an increase in the initial concentration, Figure 6(c). The increase in the initial dye concentration caused an increase in the loading capacity of the adsorbent and this may be due to the high driving force for mass at a high initial dye concentration [20]. In other words, the residual concentration of dye molecules will be higher for higher initial dye concentrations. In the case of lower concentrations, the ratio of the initial number of dye molecules to the available adsorption sites is low and subsequently the fractional adsorption becomes independent of the initial concentration.

\subsubsection{Effect of Contact time}

Maximum adsorption of indigo dye was achieved after 1 hour. The preliminary experiments showed that the adsorption of indigo dye is fast at the initial stages and becomes slower near the equilibrium. The rate of indigo adsorption onto the fiber is very rapid during the initial 2 hours and decreases thereafter, as can be seen from Figure 6(d). The time profile of indigo uptake is a single, smooth, and continuous curve leading to saturation, suggesting possible monolayer coverage of indigo dye on the surface of the coconut fibre adsorbent. 

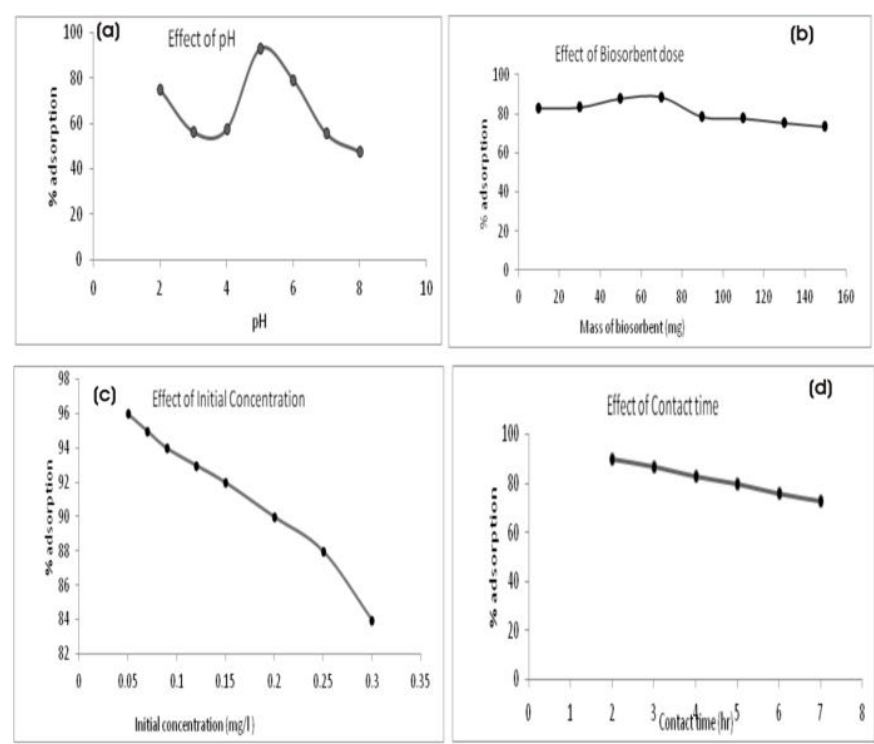

Figure 6: Effects of (a) pH (b) adsorbent dose (c) Initial dye concentration (d) time; on the adsorption of indigo dye by coconut shell from aqueous solution

\subsection{Adsorption Isotherms}

The Langmuir isotherm model proposed by Langmuir [15] is based on the assumption that adsorption occurs at specific homogenous sites within the adsorbent. It explains monolayer adsorption which lies on the fact that the adsorbent has a finite capacity for the adsorbate i.e., at equilibrium; a saturation point is attained where no further adsorption can occur.

The equation below shows the Langmuir isotherm expressions:

$q_{e}=\frac{q_{\pi m x} K_{L} C_{E}}{1+K_{L} c_{E}}$

The above equation can be linearized to:

$\frac{C_{g}}{q_{\pi n x}}=\frac{1}{q_{\pi n x} K_{L}}+\frac{C_{g}}{q_{n \pi x}}$

Where $C_{e}$, is the equilibrium concentration (mg/L), $q_{e}$ is the amount of dye adsorbed per unit mass of adsorbent at equilibrium $(\mathrm{mg} / \mathrm{g}), q_{\max }$ is the theoretical maximum adsorption capacity $(\mathrm{mg} / \mathrm{g}), K_{L}$ is the Langmuir isotherm constant $(\mathrm{L} / \mathrm{mg})$. The values of $K_{L}$ and $q_{\max }$ can be determined from the slope and intercept of the linear plot of $C_{\varepsilon} q_{q_{e}}$ against $C_{e}$, Figure $7(\mathrm{a})$. The values of $\mathrm{R}^{2}, \mathrm{~K}_{\mathrm{L}}$ and $q_{\max }$ from the Langmuir isotherm are listed in Table 1. The negative value of the $\mathrm{K}_{\mathrm{L}}$ for indigo dye indicates that adsorption of indigo dye on modified coconut shell was difficult and it may be due to an increase in ionic radius, which led to an increase in charge density, thus reduction in adsorption capacity.

The Freundlich isotherm model [16] is another most widely applied isotherm in explaining adsorption. The model applies to adsorption on heterogeneous surfaces with interaction between adsorbed molecules. It assumes that adsorption energy exponentially decreases on the completion of the sorptional centres in the adsorbent [21].

The Freundlich equation is given as:

$$
q_{e}=K_{F} C_{e}^{1 / n}
$$

where $q_{e}$ is the amount of dye adsorbed per unit mass of adsorbent at equilibrium ( $\mathrm{mg} / \mathrm{g}), \mathrm{C}_{e}$ is the equilibrium concentration $(\mathrm{mg} / \mathrm{L}), \mathrm{K}_{F}$ is the Freundlich adsorption constant related to the adsorption capacity of the adsorbent $\left(\mathrm{mg}^{1-1 / n} \mathrm{~L}^{1 / \mathrm{n}} \mathrm{g}^{-1}\right.$ ) and $\mathrm{n}$, a dimensionless constant, which can be used to explain the extent of adsorption and the adsorption intensity between the solute concentration and adsorbent respectively.

A linear form of the Freundlich equation is generally expressed as:

$\log q_{e}=\log K_{F}+\frac{1}{n} \log C_{e}$

The values of $K_{F}$ and $n$ are calculated from the intercepts and slopes of the plot of $\log q_{e}$ versus $\log C_{\text {e }}$ Figure 7(b) shows the Freundlich plots and the isotherm parameters derived from Freundlich plots are listed in Table 1. It is evident from the table that the value of $n$ is negative, thus showing homogenous adsorption site, which doesn't correlate with the Freundlich assumption.

The Temkin isotherm model [17] takes into account adsorbent - adsorbate interactions. This model assumes that the heat of adsorption of all the molecules in the layer decreases linearly with coverage due to adsorbent - adsorbate interactions, and adsorption is characterized by a uniform distribution of binding energies, up to some maximum binding energy. The linear form of Temkin isotherm is given as:

$$
q_{e}=B_{1} K_{T}+B_{1} \ln C_{e}
$$

Where $B_{1}$ is the Temkin constant related to the heat of adsorption and is given as:

$$
B_{1}=\frac{R_{Y}}{b}
$$

where $B_{1}$ is related to the heat of adsorption. $K_{T}$ is the equilibrium binding constant $(\mathrm{L} / \mathrm{mg})$. The values of $\mathrm{K}_{T}$ and $B_{1}$ obtained from the intercepts and slopes of the plots of $q_{e}$ versus $\ln C_{e}$, Figure $7(\mathrm{c})$ are summarized in Table 1.

All the three isotherm models showed a good correlation coefficient with the experimental data $\left(R^{2}>\right.$ 0.90) (Table 1), which suggests that the adsorption data obtained in the present study could be said to fit the three isotherm models. However, Langmuir isotherm had the highest correlation coefficient of $\left(R^{2}: 0.99\right)$ and thus could be considered as the best fit models for the adsorption process, although, the other two models can also be used to account for the adsorption process. 


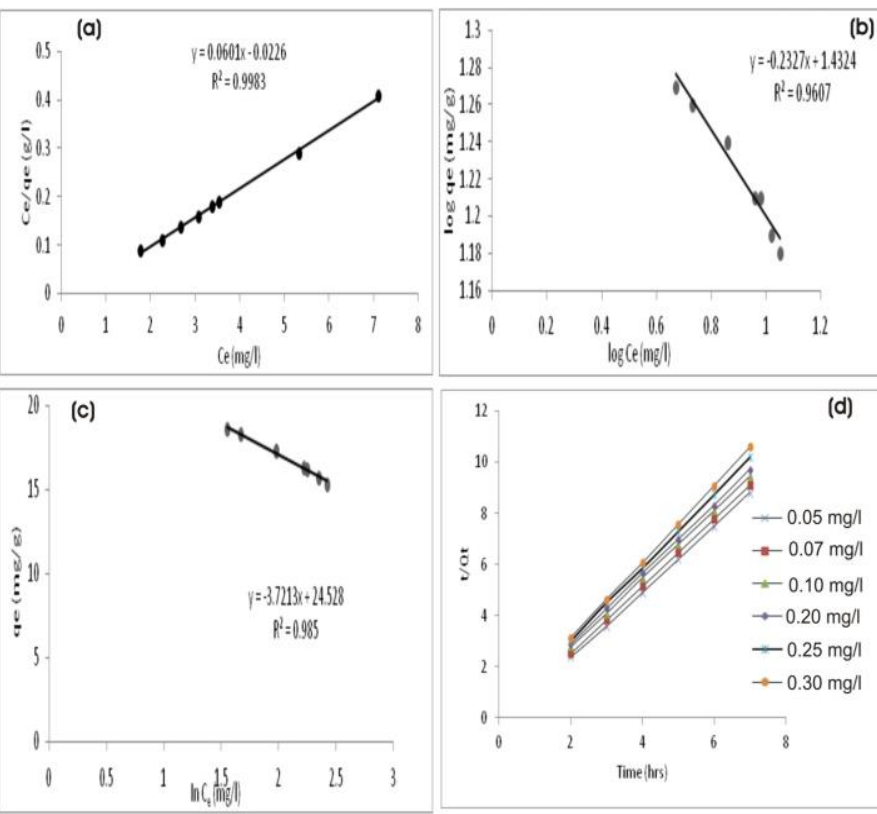

Figure 7: Isotherm plots for the adsorption of indigo dye onto coconut shell at $25^{\circ} \mathrm{C}$

(a) Langmuir, (b) Fredluich (c) Temkin and (d) Pseudosecond order Kinetic plot of adsorption on indigo onto Coconut shell

Table 1: Isotherm parameters for the adsorption of Indigo blue dye onto coconut shell.

\begin{tabular}{|l|l|l|}
\hline Isotherm Models & Parameters & Values \\
\hline Langmuir & $q_{\max }$ & 13.68 \\
\hline & $K_{L}$ & -0.71 \\
\hline & $R^{2}$ & 0.9964 \\
\hline Freundlich & $R_{L}$ & 0.033 \\
\hline & $N$ & -4.3 \\
\hline & $K_{F}$ & 27.06 \\
\hline Temkin & $R^{2}$ & 0.9607 \\
\hline & $B_{1}$ & 3.72 \\
\hline & $K_{T}$ & 0.152 \\
\hline & $R^{2}$ & 0.985 \\
\hline
\end{tabular}

\subsection{Adsorption Equilibrium kinetics}

The pseudo second order model first proposed by Blanchard et al., [22] is based on the adsorption capacity and can predicts the behaviour for the adsorption process for all dye concentrations. It can also be used to predict chemisorption processes. The pseudo second order kinetics model for the adsorption process can be represented with the expression [23]:

$$
\frac{\pi}{q_{\mathrm{i}}}=\frac{1}{\mathrm{~K}_{2} q_{\mathrm{I}}^{2}}+\frac{1}{q_{\mathrm{x}}} t
$$

Where $K_{2}$ is the rate constant of pseudo-second order adsorption $\left(\mathrm{gmg}^{-1} \mathrm{~min}^{-1}\right)$.
Figure 7(d) shows pseudo-second order plots for the adsorption process at six different concentrations of the dye, $K_{2}$ and $q_{e}$ values were determined from the intercepts and slopes of the linear plots respectively and are shown in Table 2. The correlation coefficient $\left(R^{2}\right)$ value for the dye concentration range studied was unity indicating a perfect fit of the process to the second-order kinetic model and its applicability in explaining adsorption data.

Table 2: Pseudo second order Kinetic parameters for adsorption of indigo dye by coconut shell

\begin{tabular}{|c|c|c|c|c|c|c|}
\hline $\begin{array}{l}\mathrm{CO} \\
\mathrm{NC} . \\
(\mathrm{mg} / \mathrm{L})\end{array}$ & $\begin{array}{l}q_{q_{e} \exp } \\
\left(\mathrm{m}_{Q} / L\right)\end{array}$ & $\begin{array}{l}q_{e, \exp } \\
(\mathrm{mg} / \Omega)\end{array}$ & $\begin{array}{l}K_{2} \\
(Q / \text { mgmin })\end{array}$ & $\begin{array}{l}q_{e_{\text {, calc }}} \\
(\mathrm{mg} / \mathrm{L})\end{array}$ & $\begin{array}{l}q_{e_{,} \text {cals }} \\
{[\mathrm{mg} / \mathrm{g}]}\end{array}$ & $R^{2}$ \\
\hline 0.05 & 0.079 & 10.12 & 1.20 & 0.078 & 1.30 & $\begin{array}{l}1 . \\
00\end{array}$ \\
\hline 0.07 & 0.076 & 10.00 & 2.00 & 0.077 & 1.00 & $\begin{array}{l}1 . \\
00\end{array}$ \\
\hline 0.1 & 0.074 & 9.70 & 5.88 & 0.076 & 10.00 & $\begin{array}{l}0 . \\
99\end{array}$ \\
\hline 0.2 & 0.073 & 9.60 & 8.54 & 0.073 & 9.00 & $\begin{array}{l}0 . \\
99\end{array}$ \\
\hline 0.25 & $\begin{array}{l}0.069 \\
5\end{array}$ & 8.00 & 20.00 & 0.070 & 9.20 & $\begin{array}{l}0 . \\
99\end{array}$ \\
\hline 0.30 & $\begin{array}{l}0.065 \\
7\end{array}$ & 6.80 & 25.00 & 0.068 & 8.75 & $\begin{array}{l}0 . \\
99\end{array}$ \\
\hline
\end{tabular}

\section{CONCLUSION}

Results obtained from this work revealed that chemically modified coconut shell is an effective low cost adsorbent for the removal of indigo blue dye from aqueous solutions. Equilibrium parameters calculated from Langmuir, Freundlich and Temkin isotherms are useful for the explanation of the mechanisms of the adsorption process as indicated by the good linear correlation coefficient values. The adsorption process was concluded to be chemisorption with the adsorbent surface energetically homogenous. The adsorption kinetic data were best described by the pseudosecond order kinetic model.

\section{ACKNOWLEDGEMENTS}

The authors wish to acknowledge the support and cooperation of the technologists of the Department of Chemistry, University of llorin during the course of the laboratory experiments

\section{COMPETING INTERESTS}

Authors declare that no competing interests exist.

\section{Authors' Contributions}

Olaniyi k. Yusuff designed the study, wrote the protocol, and corrected the final draft of the manuscript. Omowunmi D. Agboola managed the 
analyses of the study and wrote the first draft of the manuscript. Modinah A.O. Abdul Raheem managed the literature searches and corrected the final draft of the manuscript. All authors read and approved the final manuscript.

\section{REFERENCES}

1. Li, Q. H. The chemical constituents of QingDai. Acta Bot. Sin. 1987:29:67-72

2. Hoessel, R., Leclerc, S., Endicott, J.A., Nobel M.E., Lawrie, A., Leost, M., Damiens E., Marie D., Marko, D., Niederberger E, Tang W, Eisenbrand G, Meijer L.(1999): Indirubin, the active constituent of a Chinese antileukaemia medicine, inhibits cyclindependent kinases. Nat. Cell Biol., 1:60-67

3. Wang X. Q., Gan W. J., Yang T. Y., Wang Z. C., Qiao L. S., Qi R. B. Effect of induribin on the cell surface of chronic myelocytic leukemia. Tianjin Med. J. 1984:12:707 - 710

4. Stasiak, N., kukula-Koch, W., and Glowniak , K. Acta Pol. Pharm. 2014:71(2):215 - 221.

5. Moran C., Hall, M.E., Howell, R.C. Effects of sewage treatment on textile effluent. J. Soc. Dyers Colour. 1997:113:272-274.

6. Grof, K.A., Byung, R.K. Textile wastes. J. Water Pollut. Control Fed. 1989:61:872-876.

7. Rao, K.L.L.N., Krishnaiah, K., Ashutush.Colour removal from a dye study industry effluent using activated carbon. Indian J. Chem. Technol. 1994:1:13-19.

8. Etim, U.J, Umoren, S.A., Eduok, U.M. Coconut coir dust as a low cost adsorbent for the removal of cationic dye from aqueous solution, J. Saudi Chem. Soc. 2016:20:S67-S76

9. Ramakrishna, K. R. and Viraraghavan, T. Dye removal using low cost adsorbents. Water Sci. technol. 1997:36(2-3):189 - 196.

10. Crini, G. Non-conventional low-cost adsorbents for dye removal: A review. Bioresour. technol. 2006:9(9):1061 - 1085.

11. Gupta V. K and Suhas. Application of low-cost adsorbents for dye removal - A review. J. Environ. Manage. 2009:90(8):2313 - 2342

12. Dabrowski A. Adsorption - from theory to practice, Adv. Colloid Interface Sci. 2001:93:135-224
13. Sollars, C. J., San Miguel, G., Fowler, G. D., Dall'Orsco, M. Porosity and surface characteristics of activated carbons produced from waste tyre rubber. J. Chem. Technol. Biot. 2001:77:1-8

14. Raghavacharya, C. Colour removal from industrial effluents: a comparative review of available technologies. Chem. Eng. World 1997:32:53-54.

15. Langmuir, I. The Adsorption of Gases on Plane Surfaces of Glass, Mica and Platinum. J. Am. Chem. Soc. 1918:40:1361-1403.

16. Freundlich, H. Z. Concerning Adsorption in Solutions. Z. Phys. Chem. 1906:57: 444 - 448.

17. Tempkin, M.I, Pyzhev, V. Kinetics of ammonia synthesis on promoted iron catalyst, Acta Phys. Chim. USSR 1940:12:327-356

18. Arsyad, M.; Wardana, I.N.G.; Pratik T.O.; Irawan, Y.S. The morphology of coconut fiber surfaqce under chemical treatment. Revista Matérial, 2015:20(1):169 - 177,

19. Fernelius, W. C. Renfrew, E. E. Indigo. J. Chem. Ed., 1983:60 (8):633-634.

20. Bulut $Y$, Aydin H. A kinetics and thermodynamics study of methylene blue adsorption on wheat shells. Desalination 2006:194:259-267.

21. Crini, G., Badot, P.M. Application of chitosan, a natural aminopolysaccharide, for dye removal from aqueous solutions by adsorption processes using batch studies: a review of recent literature. Prog. Polym. Sci. 2008:33:399-447.

22. Blanchard, G., Maunaye, M., Martin, G. Removal of heavy metals by means of natural zeolites. Water Res. 1984:18 (12):1501 1507.

23. Ho, Y.S. and McKay, G. Pseudo-second order model for sorption processes. Process Biochem. 1999:34(5):451 - 465 